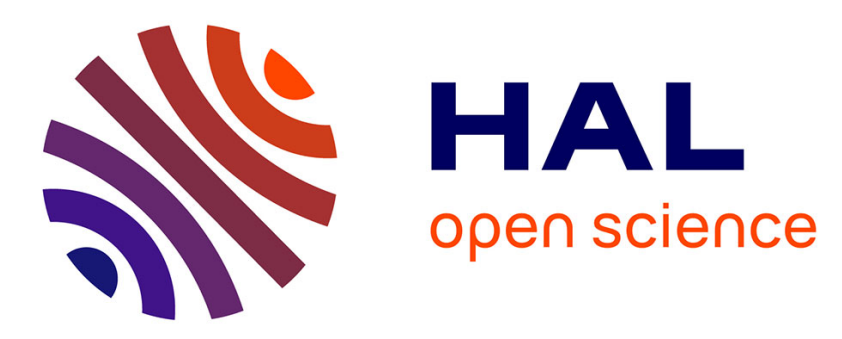

\title{
Impact of biochemical design on estrogen receptor/estrogen response element interaction by surface plasmon resonance technology
}

Denis Habauzit, Sandrine Bayle, David Benimelis, Joel Chopineau, Benoît Roig

\section{To cite this version:}

Denis Habauzit, Sandrine Bayle, David Benimelis, Joel Chopineau, Benoît Roig. Impact of biochemical design on estrogen receptor/estrogen response element interaction by surface plasmon resonance technology. Archives of Biochemistry and Biophysics, 2014, 541, pp.61-66. 10.1016/j.abb.2013.11.006 . hal-00936061

\section{HAL Id: hal-00936061 https://hal.science/hal-00936061}

Submitted on 31 Mar 2014

HAL is a multi-disciplinary open access archive for the deposit and dissemination of scientific research documents, whether they are published or not. The documents may come from teaching and research institutions in France or abroad, or from public or private research centers.
L'archive ouverte pluridisciplinaire HAL, est destinée au dépôt et à la diffusion de documents scientifiques de niveau recherche, publiés ou non, émanant des établissements d'enseignement et de recherche français ou étrangers, des laboratoires publics ou privés. 


\section{Impact of biochemical design on estrogen receptor / estrogen response element interaction by surface plasmon resonance technology}

Denis Habauzit $^{1,2}$, Sandrine Bayle ${ }^{1}$, David Benimelis ${ }^{3}$, Joel Chopineau ${ }^{3,4}$, Benoit Roig ${ }^{3,5,6}$

1/ Laboratoire Génie de l'Environnement Industriel, Ecole des Mines d'Alès, 6 Avenue de Clavières, 30319, Alès Cedex, France.

2/ INSERM U1085, Institut de Recherche en Santé, Environnement et Travail (IRSET), Equipe "TREC", Biosit, Université de Rennes 1, Campus de Beaulieu, bât 13, 263 avenue du Général Leclerc, CS 74205, 35042 RENNES cedex, France.

3/ Université de Nîmes, Rue Georges Salan, 30021 Nîmes, France

4/ Institut Charles Gerhardt Montpellier, UMR 5253 CNRS-ENSCM UM2-UM1 Ecole

Nationale Supérieure de Chimie, Montpellier, France

5/ EHESP Rennes, Sorbonne Paris Cité, Avenue du Professeur Léon Bernard- CS 74312, 35043 Rennes Cedex, France

6/ INSERM U1085-IRSET, LERES, France

\section{Correspondence}

Dr D. Habauzit

IRSET, Institut de Recherche en Santé, Environnement et Travail; Equipe "TREC", Université de Rennes 1; Biosit; Campus de Beaulieu- bât 13; 263 Avenue du Général Leclerc; CS 74205; 35042 RENNES cedex, France

Phone: +33-2 23236132

Fax: +33-2 23236794

E-mail : denis.habauzit@ univ-rennes1.fr / benoit.roig@ unimes.fr 


\section{Abstract}

The estrogen receptor (ER) is a transcription factor that binds under $17 \beta$ estradiol (E2) stimulation as homodimer to a short DNA consensus sequence named estrogen response element (ERE). The ER/ERE interaction has been assessed by several research groups through different methodologies notably by surface plasmon resonance (SPR) techniques. The biochemical parameters and conditions (solvent, ER concentration, salt, time and temperature) used to prepare samples before analysis were very different from one study to another. But no studies have aimed to compare the effect of these modifications on ER/ERE interaction. Therefore the main objective of the present paper was to assess the influence of biochemical parameters onto the ER/ERE interaction with the final aim to improve the comprehension of this interaction. Our results highlighted that parameters like solvent, ER concentration, salt and surfactant concentration, temperature and time deeply modify ER/ERE interaction. Nevertheless, the dimer formation under E2 stimulation occurred with all tested conditions. Altogether, incubation parameters of ER with E2, deeply modify its binding level onto ERE. These data constitute an important key point to consider for the improvement of ER/ERE detection method depending upon the aim of the study (interaction measurement, environmental detection, development of new technologies or devices).

Keywords: Surface plasmon resonance, estrogen, estrogen receptor, dimerization, solvent, temperature 


\section{Introduction}

The estrogen receptor (ER) belongs to the family of nuclear receptor [1]. In cell the activity of this transcription factor (TF) is mainly due to its activation by steroid especially 17 $\beta$ estradiol (E2). In cells, this TF is implicated in several cellular function and orientation like in the proliferation [2], in the differentiation [3, 4], in the protection [5], and finally in gene expression.

Several experiments have been developed for the comprehension and for the characterization of the mechanism by which ER is activated by ligand and its binding capacity as a homodimer (ER/E2) $)_{2}$ to a specific DNA consensus sequence (ERE) located upstream of some estrogenic regulated genes. In this way several biophysical tools have been developed to explore the interaction phenomena such as fluorescence anisotropy [6-8], surface plasmon resonance (SPR) [9-12], FRET [13], electrochemical [14-16], resonant waveguide [17]. The main objectives were to determine the estrogenic compounds/ER interaction properties [1820], the ER/ER dimerization phenomena [13, 21], ER/ERE interaction mechanism and properties under estrogenic stimulation $[9,10]$.

Now these interactions are used for several purposes such as i) comprehension of molecular interaction; ii) measurement of ER interaction properties; iii) evaluation of the estrogenic potential of compounds that mimic the natural hormone; iv) the development of new methods for environmental monitoring with direct and fast quantification of estrogenic compounds and finally; v) their use as a classical model of interaction for the development of new devices or apparatus for the biophysical measurement. 
Among biophysical methods, SPR allows real time monitoring of direct interaction between molecules. The signal variation, expressed in resonance unit (RU), is proportional to the amount of bound molecules [11]. Recently, SPR technology has been extensively developed in the environmental field, especially for the assessment of molecular interactions or for the detection of pollutant $[11,22]$. These developments are first due to its sensitivity without a pre-concentration step (low detection limit (ng/L)) [23]. Then, there is currently a high development of miniaturized portable systems [24]. However this technique requires knowledge on the interaction considered: in the case of estrogenic compounds, the interaction between the compound (like E2) and the estrogen receptor (ER) characterized by ER dimerization and bounding with the nucleic acid (ERE). Different SPR systems have been used to characterise notably the estrogenic compounds/ER interaction properties [18-20], the ER/ER dimerization [21], the ER/ERE binding mechanisms [9, 10, 12, 25-31], and ER interaction with some other transcription factors like SP1 [32].

In the characterization of (ER/E2)/ERE interaction [9, 10, 12, 25-31] (Fig. 1), various experimental conditions have been used such as solvent to dissolve E2, the range of ER concentration and the ER/E2 incubation parameters (Table 1) without any justifications. The diversity of the experimental conditions makes the establishment of this experimental approach difficult. Moreover, these variations of experimental design could explain few authors did not reproduce the increase of the ER binding level by SPR in the presence of E2 [30]. Our work aims to homogenate protocol depending onto the aim of the study. Therefore we evaluate the impact of i) the solvent used in ER/ERE and on (ER/E2)/ERE interactions; ii) the ER concentrations (10 $\mathrm{nM}$ or $50 \mathrm{nM})$; iii) the buffer salt concentration; iv) the temperature and time effects on dimer formation; and v) the temperature and time effects onto the dimer preservation. We aim to determine the optimum conditions for (ER/E2)/ERE interaction 
analysis by considering the dimer formation best conditions, its preservation and its detection via a SPR system either for its use in fundamental studies or in screening purpose. 


\section{Materials and methods}

\subsection{Reagents}

All chemicals used in this work were of analytical grade. Tris buffer, Tween 20, dimethyl sulfoxide (DMSO), methanol and 17ß-estradiol (E2) were purchased from SigmaAldrich (St Quentin Fallavier, France).

TNMT (Tris, $\mathrm{NaCl}, \mathrm{MgCl}_{2}$, and Tween) buffer contains $50 \mathrm{mM}$ Tris $\mathrm{HCl}, 150 \mathrm{mM}$ $\mathrm{NaCl}, 10 \mathrm{mM} \mathrm{MgCl} 2,0.05 \%$ Tween 20, pH 7.5. Three additional modified TNMT buffers were prepared: TNMT methanol $(0.2 \%$ vol/vol $)$, TNMT DMSO $(0.2 \%$ vol/vol $)$ and TNMT solvent free buffers. In the last one, E2 is prepared firstly in methanol then $2 \mu \mathrm{L}$ is evaporated and E2 (solvent free) is dissolved in TNMT.

Human recombinant ER $\alpha$ and Estrogen Response Element (ERE) used have been previously described [10].

\subsection{Solutions preparation}

\subsubsection{E2 solution}

E2 was dissolved in methanol or in DMSO and added to running buffer to prepare E2 standards with final concentrations ranging from 2 to $2000 \mathrm{nM}$. Final methanol or DMSO concentrations were $0.2 \%$ (vol/vol) in TNMT buffer or milliQ water. 


\subsubsection{ER solution}

ER solutions were diluted in TNMT buffer for final concentration of $20 \mathrm{nM}, 30 \mathrm{nM}$ or $100 \mathrm{nM}$.

\subsubsection{ER/E2 solution}

A volume of buffer containing or not E2 was mixed with an equal volume of ER solution. The final concentration of solvent and of ER was therefore $0.1 \%$ and 10,15 or 50 $\mathrm{nM}$ respectively.

\subsection{SPR experiments}

Biacore analysis has been performed at $25^{\circ} \mathrm{C}$ on Biacore 1000 apparatus. ERE was firstly bound onto the activated sensor chip surface streptavidin's coated (SCSA) by injection of ERE solution (450 $\mathrm{nM}$ diluted in running buffer) at a flow rate of $5 \mu \mathrm{L} / \mathrm{min}$.

The ER/ERE interaction was measured by injecting $40 \mu \mathrm{L}$ of the ER in the presence or in the absence of E2 onto the ERE bound sensor chip surface with a constant flow rate of 20 $\mu \mathrm{L} / \mathrm{min}$. After reversion to running buffer, the dissociation phase was recorded for $180 \mathrm{~s}$. After each injection, the surface was regenerated by injection of $20 \mu \mathrm{L}$ of a $0.1 \%$ SDS solution $(20 \mu \mathrm{L} / \mathrm{min})$ followed by rinsing with running buffer for $2 \mathrm{~min}$. One cycle of regeneration was enough to remove all bound proteins.

The quantification of the binding ER/ERE was determined from the sensorgram $10 \mathrm{~s}$ 
after the reversion to running buffer.

Incubation kinetics for the binding of ER with E2 and the binding level offer onto ERE were assessed at different temperatures $0.1^{\circ} \mathrm{C}, 21.6^{\circ} \mathrm{C}, 25^{\circ} \mathrm{C}, 26.5^{\circ} \mathrm{C}, 30^{\circ} \mathrm{C}$ and compared to the reference incubation conditions (overnight at $4^{\circ} \mathrm{C}$ ) determined in previous works [10]. Some experimental parameters such as conditioning of the surface and running buffer alone (TNMT buffer) have been previously described [10]. 


\section{Results and discussion}

Fig. 1 and table 1 summarize the method and the experimental parameters generally described in the literature for the detection of estrogenic compound by SPR (based on ER/ERE interaction). However, the parameters differ from one study to another as for example:

- The solvent for E2 solubilization was either DMSO, ethanol or methanol and was used interchangeably without any justification.

- The concentrations of ER ranged from $10 \mathrm{nM}$ up to $270 \mathrm{nM}$. These concentration values could influence the concentration of E2 needed to ind uce the ER dimerization.

- The conditions of temperature and time used for ER/E2 incubation (to reach the dimerization of $\mathrm{ER}$ in the presence of $\mathrm{E} 2)$ range from $37^{\circ} \mathrm{C} / 5$ minutes to $4^{\circ} \mathrm{C} /$ overnight.

However, for a more widespread use of SPR in this purpose, there is a need of standardized protocols. In the following, we tried to bring a light on the best conditions needed for the ER/ERE interaction study by SPR either for fundamental study purpose as well as for optimizing our endocrine disrupting chemical detection method. 17- $\beta$-estradiol (E2) was chosen as model estrogenic compounds.

\subsection{Solvent effect on the ER / ERE interaction.}

The solubility of E2 in pure water is relatively low $\left(5.5 \mu \mathrm{M}\right.$ at $25^{\circ} \mathrm{C}$ and $\mathrm{pH} 7$ [33]) and consequently, a co-solvent was used to improve the dissolution of E2. However, the 
solvents modify the parameters of analysis (bulk refractive index corresponding to the blank of analysis (Fig. S1.A)) but also could modify the ER/ERE interaction either directly or indirectly by impacting the ER/E2 binding or then (ER/E2)/ERE interaction.

The indirect effect of the solvent on ER/ERE interaction has been evaluated by using the dimerization of ER in the presence of E2. The ER $(50 \mathrm{nM})$ was incubated overnight at $4^{\circ} \mathrm{C}$, with and without $\mathrm{E} 2(1000 \mathrm{nM})$ previously dissolved or not in solvent. The mixture was then injected on the ERE-SCSA. 0.1\%-DMSO buffer induced difference of the bulk refractive index when compared to the TNMT alone and TNMT-0.1\% methanol (respectively $220 \mathrm{RU}$ and $190 \mathrm{RU}$ ) in particular for DMSO (1.8 more important at $350 \mathrm{RU})$ (Fig. S1.B).

The ER binding level onto ERE is higher in TNMT-0.1\% methanol (216 RU to 480 RU, Fig. 2A), than in TNMT-0.1\% DMSO (153 to $250 \mathrm{RU}$ ) and TNMT alone (162 to 282 RU). In these conditions, the ER binding level was dependent of the solvent used for the estrogenic compound solubilisation, in particular with methanol compared to the other solvents (2.2 fold in methanol vs 1.7-1.6 in other conditions). This is due to the estrogenic effect on the dimerization process as previously described [10].

Thus, DMSO and methanol induced an opposite effect on the ER/ERE interaction: the first one decreasing the ER binding level, while the second one increasing it. Such solvent effects have been already described for other protein's solubilisation by Hirota-Nakaoka et al. [34], who described the increase of the protein solubility with DMSO compared to alcohol. Moreover, they highlighted the higher denaturant effect of DMSO due to its polarity $[34,35]$. So, DMSO could decrease the signal through its mild detergent effect. Methanol at low 
concentration may induce a better ER folding state of the protein and improved its capacity to interact with ERE.

E2 concentration influences also the ER/ERE binding SPR signal. At $50 \mathrm{nM}$ E2, the resonance unit is doubled in all buffers as previously described in TNMT- $0.1 \%$ methanol when the E2/ER molar ratio concentration reached 1:1 [10]. This ratio was verified with DMSO and solvent free buffer. Then, E2 concentrations ranging from $1 \mathrm{nM}$ to $100 \mathrm{nM}$ in TNMT solvent free, and TNMT- $0.1 \%$ DMSO or TNMT- $0.1 \%$ methanol were tested in the presence of $50 \mathrm{nM}$ of ER (Fig. 2B). Although the level of binding is influenced by the solvents, the dimerization of ER protein occurred regardless the solvent but only when the E2/ER molar ratio reached 1:1 (Fig. 2B). However, methanol produced a higher of binding level. Consequently, in the following experiments, TNMT-0.1\% methanol buffer has been used for better ER binding level monitoring. In conclusion, methanol should be used preferentially for detection methods in order to increase ER detection. But for fundamental study purpose the studies should use evaporated solvent for more physiologic conditions. In addition, the bulk refractive index linked to the solvent has been subtracted of all sensograms in the following part of the publication as advised [36].

\subsection{Effect of the ER concentration on the ligand dependent homodimerization}

In SPR experiment described in the literature (Table 1), the concentration of ER ranges from $10 \mathrm{nM}$ to $270 \mathrm{nM}$. The ER dimerization was obtained for an E2/ER ratio 1:1 when ER concentration was $50 \mathrm{nM}$ or more ([10] and present study). The influence of ER concentration was tested by measuring the binding of ER/E2 (obtained with incubation of ER at $10 \mathrm{nM}$ with E2 at $1000 \mathrm{nM}$ ) in TNMT-0.1\% methanol) onto the ERE-SCSA. E2 induced an 
increase of the ER binding level (56 to $114 \mathrm{RU}$ ) corresponding to ER dimerization under E2 stimulation (Fig. 3A). Such increase was shown reproducible: variation of 3 and $11 \%(n=3)$ respectively in the absence of E2 and in the presence of E2. E2 (concentration ranging from

$0.5 \mathrm{nM}$ to $1 \mu \mathrm{M}$ ) was then mixed with $10 \mathrm{nM}$ of ER in order to verify the dependence of the dimerization to molecular 1:1 ratio (E2/ER). Low E2 concentration (from 0.5 to $5 \mathrm{nM}$ ) induced a constant ER binding level (Fig. 3B and 3C) while E2 concentrations higher than 5 $\mathrm{nM}$ produced a strong increase (1.7 fold). This phenomenon may be attributed to the ligand dependent homodimerization of ER under E2 stimulation. Therefore the ligand dependent homodimerization occurred between 5 and $10 \mathrm{nM}$ of E2. This range of concentrations is in agreement with previous published data [11]. A higher fixation level of ER was obtained when E2/ER molar ratio is reached 1:1 whatever the concentration of ER.

\subsection{Effect of the concentration of salt and detergent decrease onto ER / ERE interaction}

Increasing concentration of E2 was prepared either in TNMT buffer or in milliQ water. Then samples were equally mixed with ER previously dissolved in TNMT buffer. The final ER concentration was $10 \mathrm{nM}$ in either TNMT or TNMT/water buffer. In this last sample the average salt and detergent concentrations were twice fold lower.

The E2 concentrations between $5.10^{-10} \mathrm{M}$ to $1.10^{-6} \mathrm{M}$ induce the increase of ER binding level from $47 \mathrm{RU}$ to $72 \mathrm{RU}$. As previously described, the ER binding level increases between 5 and $10 \mathrm{nM}$ (Fig. 4). The same evolution is observed for ER and E2 incubated with TNMT/water. Nevertheless the overall binding is upper than those observe for the TNMT buffer. The binding level is between 153 to $295 \mathrm{RU}$ in the TNMT/water assay. The increase 
factor remained also the same with respectively 1.5 in TNMT and 1.9 in TNMT/water. Unlike, the ligand homodimerization of ER under E2 stimulation, the amount of ER binding is dependent upon the salt and detergent. Lower is the salt concentration, upper is the ER binding level, as previously described [8]. Moreover, Tween 20 allows the dissociation of molecules that are bound with a low free energy. Decrease of tween concentration could allow the increase of nonspecific bounding of ER [37] but ameliorates the ER detection sensitivity.

\subsection{Effect of incubation conditions for dime $r$ formation}

In order to gain deeper insight on the ER dimerization, influence of time and temperature were assessed. The dimer could be obtained more rapidly for a temperature above $4^{\circ} \mathrm{C}$. As previously published [10], overnight incubation at $4{ }^{\circ} \mathrm{C}$ during 12 hours allows to double the ER binding level and the complex is stable up to 60 hours when preserved at $4{ }^{\circ} \mathrm{C}$. Moreover, as shown in Table 1, an incubation time ranging from 5 min to overnight, with temperature from $0^{\circ} \mathrm{C}$ to $37.5^{\circ} \mathrm{C}$ has been used $[9,10,12,25-31,38]$. For the following, ER dimerization by using $4{ }^{\circ} \mathrm{C}$ overnight was considered as the standard dimerization conditions. ER was mixed with or in the absence of $\mathrm{E} 2$ at 5 temperatures $\left(0.1^{\circ} \mathrm{C}, 21.6^{\circ} \mathrm{C}, 25^{\circ} \mathrm{C}, 26.5^{\circ} \mathrm{C}\right.$, $30^{\circ} \mathrm{C}$ ) for $0 \mathrm{~min}$ to overnight and injected onto the ERE-SCSA. For each temperature, ER/ERE binding level has been monitored as a function of time (Fig. S2 and 5).

Whatever the temperature and the presence or not of E2, the ER/ERE binding level decreased as a function of time (Fig. 5 and S2.B). However, the decrease was more important when the temperature increased (Fig. 5 and S2.B). Without E2, and after about 400 min of incubation, the decrease of SPR response reached $0.02,0.54,0.60,0.84$ and $0.74 \mathrm{RU} / \mathrm{min}$ at 
respectively $0.1{ }^{\circ} \mathrm{C}, 21.6^{\circ} \mathrm{C}, 25^{\circ} \mathrm{C}, 26.5^{\circ} \mathrm{C}, 30^{\circ} \mathrm{C}$. With $\mathrm{E} 2$, the decrease was $0.02,0.27,0.48$, 0.65 , and 0.69 at respectively $0.1^{\circ} \mathrm{C}, 21.6^{\circ} \mathrm{C}, 25^{\circ} \mathrm{C}, 26.5^{\circ} \mathrm{C}$ and $30^{\circ} \mathrm{C}$. The decrease of ER/ERE binding level was then faster without E2. In addition, the protective effect of E2 was more marked at low temperatures: in the absence of E2, the ER/ERE binding decrease was 1.8 times faster than with $\mathrm{E} 2$ at $21.6^{\circ} \mathrm{C}$ while it was 1.1 times faster at $30{ }^{\circ} \mathrm{C}$. These data were consistent with stability experiments in thermal denaturation, in which E2 promoted an inhibition of ER denaturation [38, 39].

However, dimerization was observed (Fig. 5 and S2.B) in all cases except for $0.1^{\circ} \mathrm{C}$ (incubation on ice), probably due to a lack of molecular diffusion in sample. The condition of the dimer formation was summarized in Fig. 5. The time required to observe the dimer decreased with the temperature increase. For example, less than 90 min were necessary at $26.5^{\circ} \mathrm{C}$ showing the possibility of a one day test. Nevertheless, the binding level and the increase were weak. In this way the parameters previously described [10], $4^{\circ} \mathrm{C}$ overnight, seems to be a better protocol for ER dimerization monitoring in fundamental study of ER/ERE interaction. For environmental monitoring, faster analysis is possible with incubation during $90 \mathrm{~min}$ at $26.5^{\circ} \mathrm{C}$. Finally, the variability of the ER binding level depending upon the incubation time and temperature could explain why Pearson et al (2001) [30] did not reproduce the increase of the ER binding level by SPR neither at $4^{\circ} \mathrm{C}$ or $25^{\circ} \mathrm{C}$ after 1 hour (Fig. 5).

\subsection{Stability over time of the (ER/E2)/ERE binding level after an initial incubation at $4^{\circ}$ C overnight}


Impact of time and temperature on the stability of dimer was explored after an initial incubation overnight at $4^{\circ} \mathrm{C}$. Samples were maintained up to $535 \mathrm{~min}$ at two temperatures $4^{\circ} \mathrm{C}$ and $25^{\circ} \mathrm{C}$ before analysis by SPR (Fig. 6). At $4^{\circ} \mathrm{C}$ the ER/ERE binding was stable at least for $535 \min \left(\sim 9\right.$ h), either with or without E2 (Fig. 6 and Fig. S3.A and S3.C). At $25^{\circ}$ C, the binding level of ER decreases with time. This decrease reaches 1.4 times less than the initial binding level in the absence of E2 and 3 times less than the initial binding level in the presence of E2 (Fig. 6, and Fig. S3.B and S3.D). ER binding level stability is influenced deeply by temperature even if the concentration remains the same and the previous incubation was common $\left(4^{\circ} \mathrm{C}\right.$, overnight). This decrease was probably due to thermal instability of ER, in the presence or in the absence of E2. Therefore, after an initial incubation period, samples must be conserved at $4{ }^{\circ} \mathrm{C}$ for preserving the integrity of the binding level signal and the binding level of ER is highly reproducible.

\section{Conclusion}

Several protocols have been established to study the ER/ERE interaction using SPR technology in the presence or in the absence of estradiol. The main objective of this work was to evaluate the impact of the different experimental conditions in order to impro ve the study of the ER/ERE binding and then to use this knowledge for the improvement of EDCs' test in environmental monitoring purpose. Here we evidence that the ER/ERE interaction is deeply influenced by all tested parameters such as: the solvent used the protein concentration, the time and the temperature. This diversity in experimental setup makes difficult the result comparison [30].

These results allowed drawing two strategies depending upon the aim of the study. 
- For environmental detection test: EDC should be extracted and be concentrated in methanol. The use of this solvent allowed to increases the signal intensity making the detection easier. Then the extract was diluted in TNMT and was mixed with ER protein at a final concentration of $15 \mathrm{nM}$. The ER mix with tested-water could decrease the salt and detergent concentration and therefore increase the overall ER binding level and therefore the sensitivity of the method. Finally the extract and ER were then incubated at $26^{\circ} \mathrm{C}$ during 90 minutes. Samples were then injected on ERE surface. If the sample could be not injected immediately on ERE surface, it must be conserved at $4^{\circ} \mathrm{C}$ up to their analysis. The analysis could be therefore performed in less than 2 hours and the development of this SPR technology will merely permit to decrease analysis time and improve the limit of detection thanks to the development of SPR sensitivity. Finally, the ER binding level and ER concentration will define the amount of E2 equivalent in the sample.

- For fundamental studies: incubation overnight at $4{ }^{\circ} \mathrm{C}$ should be use preferentially with no solvent or methanol only. Moreover as protocol (solvent, protein concentration, time and temperature) influence deeply the binding level of ER onto the ERE, it could be difficult to calculate easily a true affinity constant for ER. The binding level comparison between control conditions and E2 effect seems to be currently the main way in ER/ERE interaction study.

\begin{abstract}
Abbreviations
ER, estrogen receptor; ERE estrogen response element; E2, $17 \beta$ estradiol; SPR, surface plasmon resonance; RU, resonance unit; TNMT, Tris Nacl MgCl tween buffer; SCSA, sensor chip surface streptavidin's coated; DMSO, dimethyl sulfoxide; Na: not a vailable
\end{abstract}




\section{Table Legend}

Table 1: ER / E2 incubation parameters for ER / ERE interaction experime nts by SPR in literature. Na: not available

\section{Figures Legends}

Fig. 1: Assay design used in this study

\section{Fig. 2: Effect of the added solvent in TNMT buffer on ER/ERE interaction}

A: Impact of solvent on ER/ERE interaction in the presence of E2. Sensorgrams were obtained with the injection of a mix containing $50 \mathrm{nM}$ ER with $100 \mathrm{nM}$ E2 or without E2 dissolved in different solvents: in TNMT free solvent TNMT (evaporated methanol) or with $0.1 \%$ of methanol, with $0.1 \%$ of DMSO.

B: Evolution of the ligand dependent ER binding level prepared with or without DMSO and methanol.

Fig. 3: ER binding on ERE at $10 \mathrm{nM}$ as a function of $\mathrm{E} 2$ concentration diluted in $0.1 \%$ methanol-TNMT buffer

A: Sensograms obtained with the injection of $10 \mathrm{nM}$ ER, previously incubated overnight at $4^{\circ} \mathrm{C}$ with or without $1000 \mathrm{nM}$ E2. Binding level in each condition was sum up in the histogram inside the sensogram.

B: Sensorgrams obtained with injection of ER mixed with increasing amounts of E2 (from $5.10^{-11}$ to $\left.10^{-5} \mathrm{M}\right)$. Signals increased with the concentration of E2 (bottom to top). 
C: Evolution of the ligand dependent ER binding level at $10 \mathrm{nM}$ in function of E2 concentration

Fig. 4: Effect of the decrease of the salt and detergent concentration on the ER/ERE interaction

ER was equally mixed either with E2 previously dissolved in TNMT buffer or in pure water. The binding level was then monitored by SPR experiment.

Fig. 5: Impact of tempe rature and time on the dimer formation

Kinetics and ratio of ER binding level in the presence or in the absence of E2 at different temperatures obtained from Fig. S2 A\&B.

Fig. 6: Stability of ER binding level over time at $4^{\circ} \mathrm{C}$ and $25^{\circ} \mathrm{C}$ in the presence or in the absence of E2 after an initial incubation overnight at $4{ }^{\circ} \mathrm{C}$.

ER $(50 \mathrm{nM})$ in the absence or in the presence of E2 $(1000 \mathrm{nM})$ in $0.1 \%$ methanol TNMT buffer were incubated overnight at $4{ }^{\circ} \mathrm{C}$ for dimer formation. Before their injection on Biacore system, samples were then kept at $4{ }^{\circ} \mathrm{C}$ and $25^{\circ} \mathrm{C}$. The data were obtained from Figure S3. 


\section{REFERENCES}

[1] G. Kerdivel, D. Habauzit, F. Pakdel, International Journal of Endocrinology 2013 (2013) 14.

[2] D. Habauzit, A. Boudot, G. Kerdivel, G. Flouriot, F. Pakdel, Environ Toxicol 25 (2010) 495-503.

[3] D. Habauzit, G. Flouriot, F. Pakdel, C. Saligaut, Journal of Toxicology and Environmental Health, Part B: Critical Reviews 14 (2011) 300-327.

[4] Y. Merot, F. Ferriere, L. Gailhouste, G. Huet, F. Percevault, C. Saligaut, G. Flouriot, Endocrinology 150 (2009) 200-211.

[5] F. Ferriere, D. Habauzit, F. Pakdel, C. Saligaut, G. Flouriot, PLoS One 8 (2013) e69081.

[6] A. Bouter, N. Buisine, A. Le Grand, N. Mouchel, F. Chesnel, C. Le Goff, V. Le Tilly, J. Wolff, O. Sire, Biochim Biophys Acta 1799 (2010) 546-554.

[7] M. Szatkowski-Ozers, J.J. Hill, K. Ervin, C.A. Royer, J. Gorski, Mol Cell Endocrinol 175 (2001) 101-109.

[8] M. Szatkowski-Ozers, J.J. Hill, K. Ervin, J.R. Wood, A.M. Nardulli, C.A. Royer, J. Gorski, J Biol Chem 272 (1997) 30405-30411.

[9] B.J. Cheskis, S. Karathanasis, C.R. Lyttle, J Biol Chem 272 (1997) 11384-11391.

[10] D. Habauzit, J. Armengaud, B. Roig, J. Chopineau, Anal Bioanal Chem 390 (2008) 873-883.

[11] D. Habauzit, J. Chopineau, B. Roig, Anal Bioanal Chem 387 (2007) 1215-1223.

[12] W.Y. Peh, E. Reimhult, H.F. Teh, J.S. Thomsen, X. Su, Biophys J 92 (2007) 44154423.

[13] A. Tamrazi, K.E. Carlson, J.R. Daniels, K.M. Hurth, J.A. Katzenellenbogen, Mol Endocrinol 16 (2002) 2706-2719.

[14] Y.S. Kim, H.S. Jung, T. Matsuura, H.Y. Lee, T. Kawai, M.B. Gu, Biosens Bioelectron 22 (2007) 2525-2531.

[15] Z. Guo, N. Zine, P. Balaguer, A. Zhang, P. Namour, F. Lagarde, N. Jaffrezic-Renault, Electroanalysis 25 (2013) 1765-1772.

[16] S. Zhu, Y. Cao, Y. Xu, Y. Yin, G. Li, Int J Mol Sci 14 (2013) 10298-10306.

[17] C. Ge, M. Lu, S. George, T.A. Flood, Jr., C. Wagner, J. Zheng, A. Pokhriyal, J.G.

Eden, P.J. Hergenrother, B.T. Cunningham, Lab Chip 13 (2013) 1247-1256.

[18] W. Li, M. Seifert, Y. Xu, B. Hock, Environ Int 30 (2004) 329-335.

[19] R.L. Rich, L.R. Hoth, K.F. Geoghegan, T.A. Brown, P.K. LeMotte, S.P. Simons, P. Hensley, D.G. Myszka, PNAS 99 (2002) 8562-8567.

[20] M. Seifert, S. Haindl, B. Hock, Adv Exp Med Biol 444 (1998) 113-117.

[21] E. Jisa, A. Jungbauer, J Steroid Biochem Mol Biol 84 (2003) 141-148.

[22] C. Tortolini, M. Frasconi, M. Di Fusco, F. Mazzei, International Journal of Environment and Health 4 (2010) 305-322.

[23] K. Toma, M. Vala, P. Adam, J. Homola, W. Knoll, J. Dostalek, Opt Express 21 (2013) 10121-10132.

[24] P. Preechaburana, M.C. Gonzalez, A. Suska, D. Filippini, Angew Chem Int Ed Engl 51 (2012) 11585-11588.

[25] K. Asano, A. Ono, S. Hashimoto, T. Inoue, J. Kanno, Anal Sci 20 (2004) 611-616.

[26] A. Berthier, C. Elie-Caille, E. Lesniewska, R. Delage-Mourroux, W. Boireau, J Mol Recognit 24 (2011) 429-435. 
[27] E. Jisa, E. Dornstauder, S. Ogawa, S. Inoue, M. Muramatsu, A. Jungbauer, biochemical pharmacology 62 (2001) 953-961.

[28] D. Kostelac, G. Rechkemmer, K. Briviba, J Agric Food Chem 51 (2003) 7632-7635.

[29] M. Murata, K. Midorikawa, M. Koh, K. Umezawa, S. Kawanishi, Biochemistry 43 (2004) 2569-2577.

[30] J. Pearson, A. Gill, G.P. Margison, P. Vadgama, A.C. Povey, Sensors and Actuators B: Chemical 76 (2001) 1-7.

[31] H.F. Teh, W.Y. Peh, X. Su, J.S. Thomsen, Biochemistry 46 (2007) 2127-2135.

[32] S.J. Neo, X. Su, J.S. Thomsen, Anal Chem 81 (2009) 3344-3349.

[33] A. Shareef, M.J. Angove, J.D. Wells, B.B. Johnson, Journal of Chemical \& Engineering Data 51 (2006) 879-881.

[34] N. Hirota-Nakaoka, K. Hasegawa, H. Naiki, Y. Goto, J Biochem 134 (2003) 159-164.

[35] N. Hirota-Nakaoka, Y. Goto, Bioorg Med Chem 7 (1999) 67-73.

[36] R.L. Rich, D.G. Myszka, J Mol Recognit 23 (2010) 1-64.

[37] B.K. Oh, Y.K. Kim, K.W. Park, W.H. Lee, J.W. Choi, Biosens Bioelectron 19 (2004) 1497-1504.

[38] A.C. Gee, J.A. Katzenellenbogen, Mol Endocrinol 15 (2001) 421-428.

[39] A. Bouter, V. Le Tilly, O. Sire, Biochemistry 44 (2005) 790-798.

[40] X. Su, C.Y. Lin, S.J. O'Shea, H.F. Teh, W.Y. Peh, J.S. Thomsen, Anal Chem 78 (2006) 5552-5558. 
Table 1

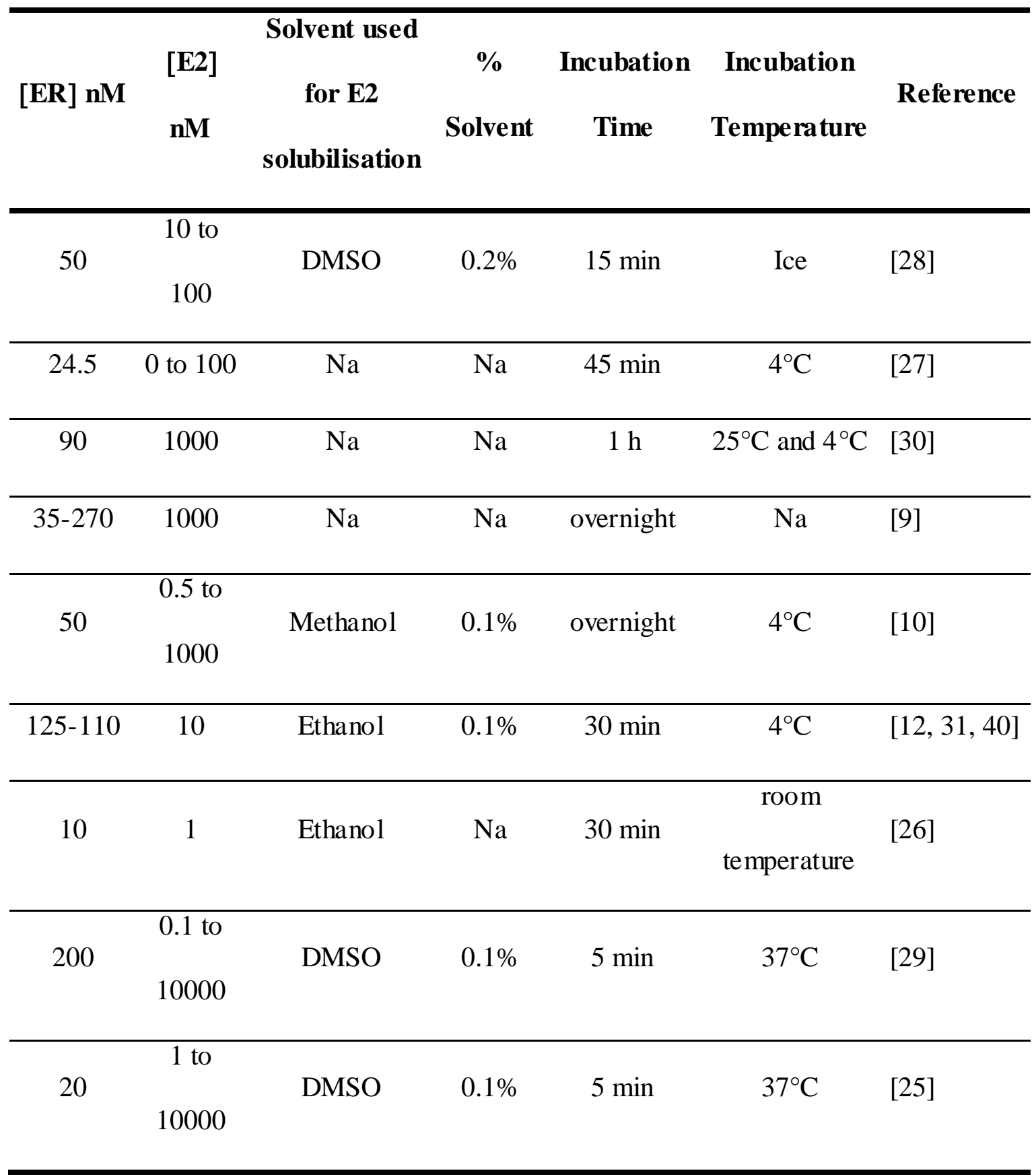


Fig. 1

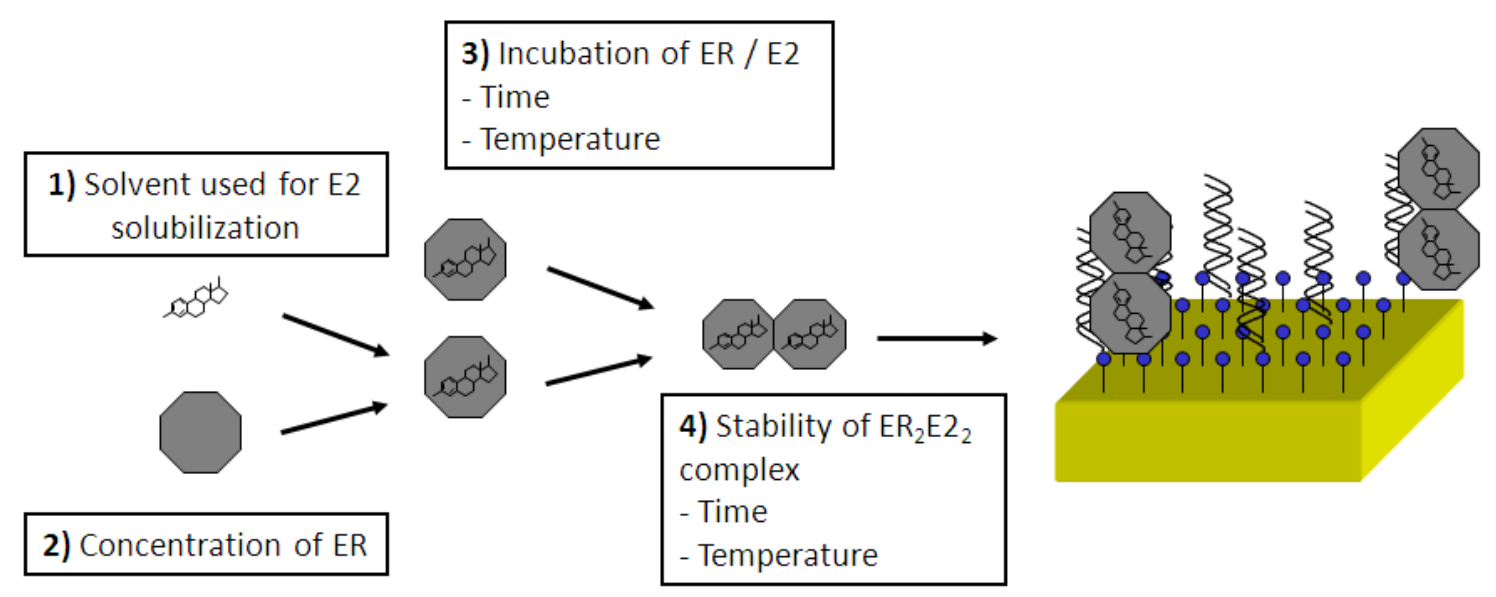


Fig. 2
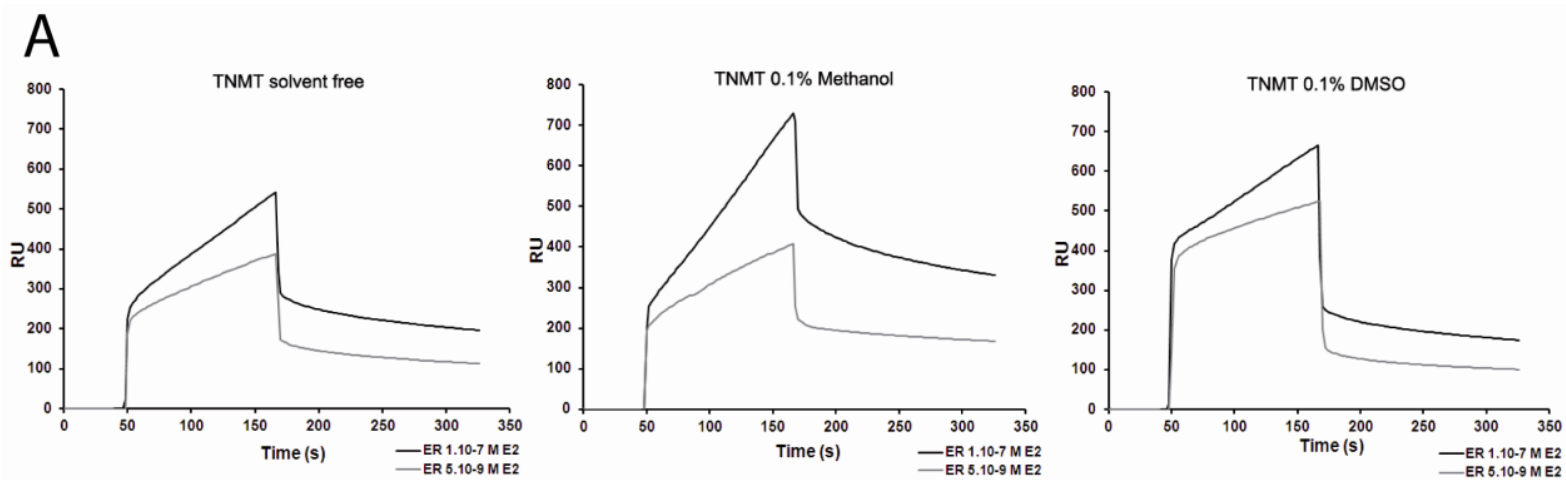

B

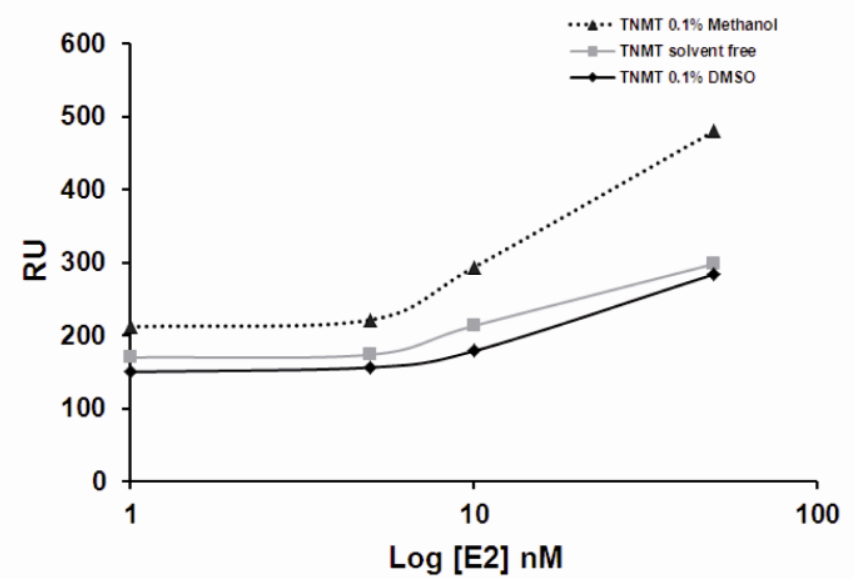


Fig. 3
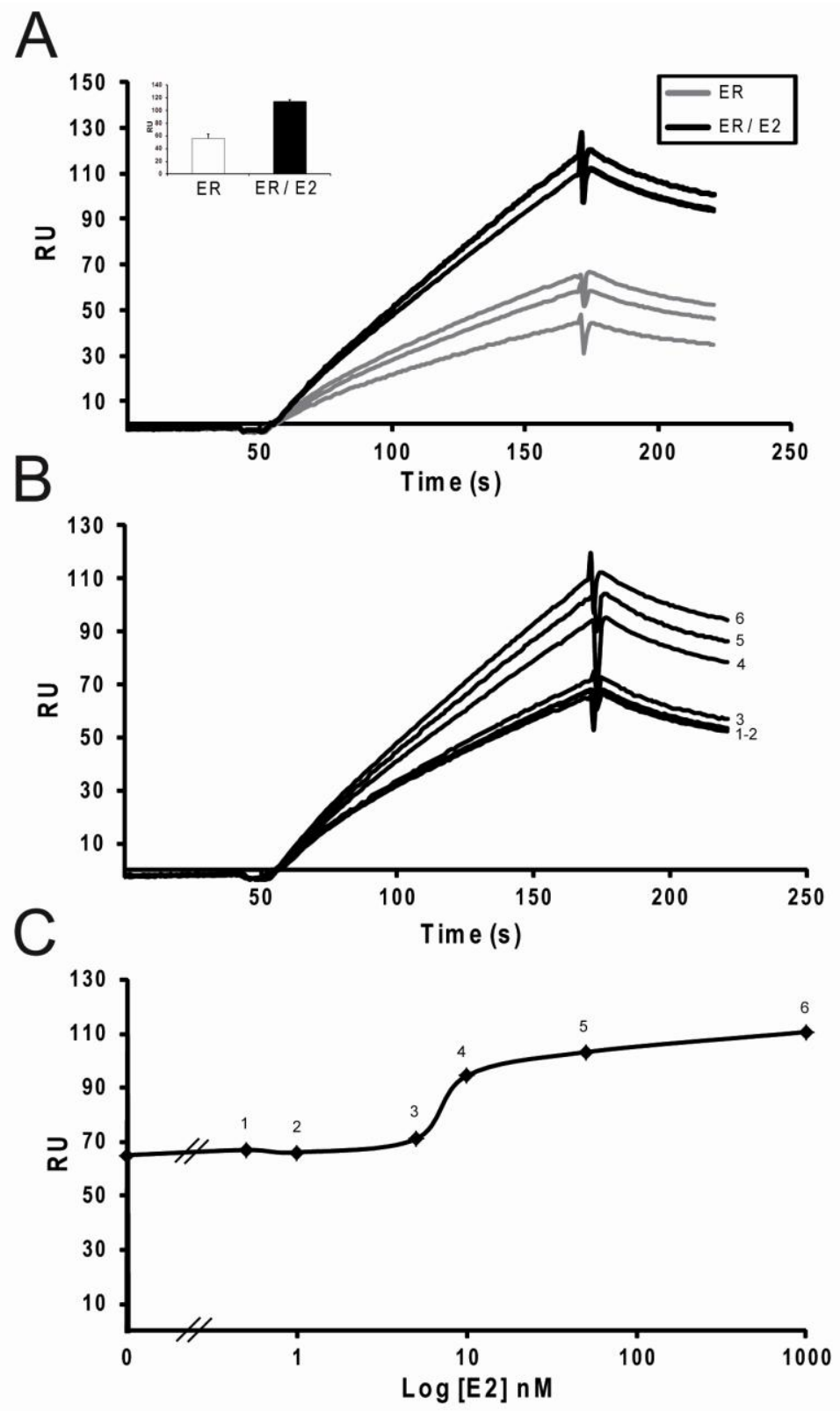
Fig. 4

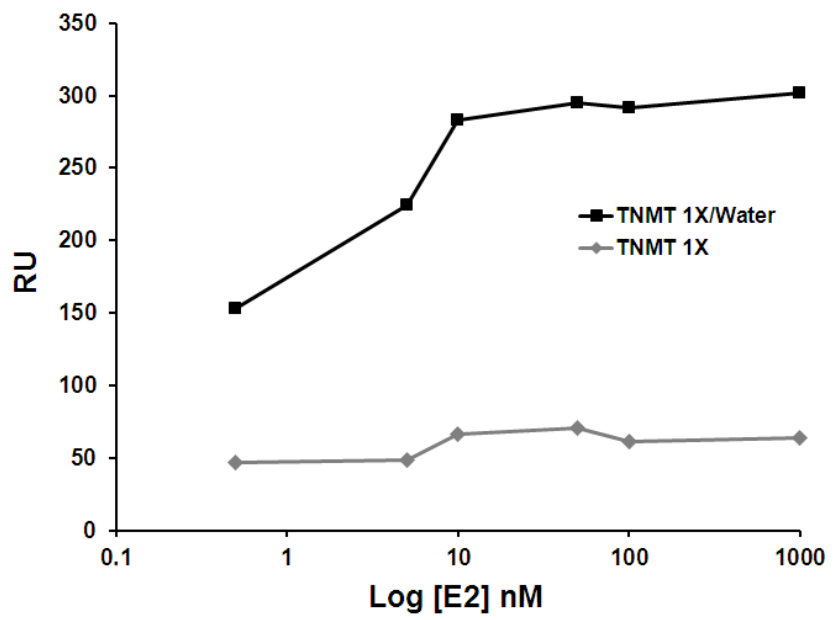


Fig. 5
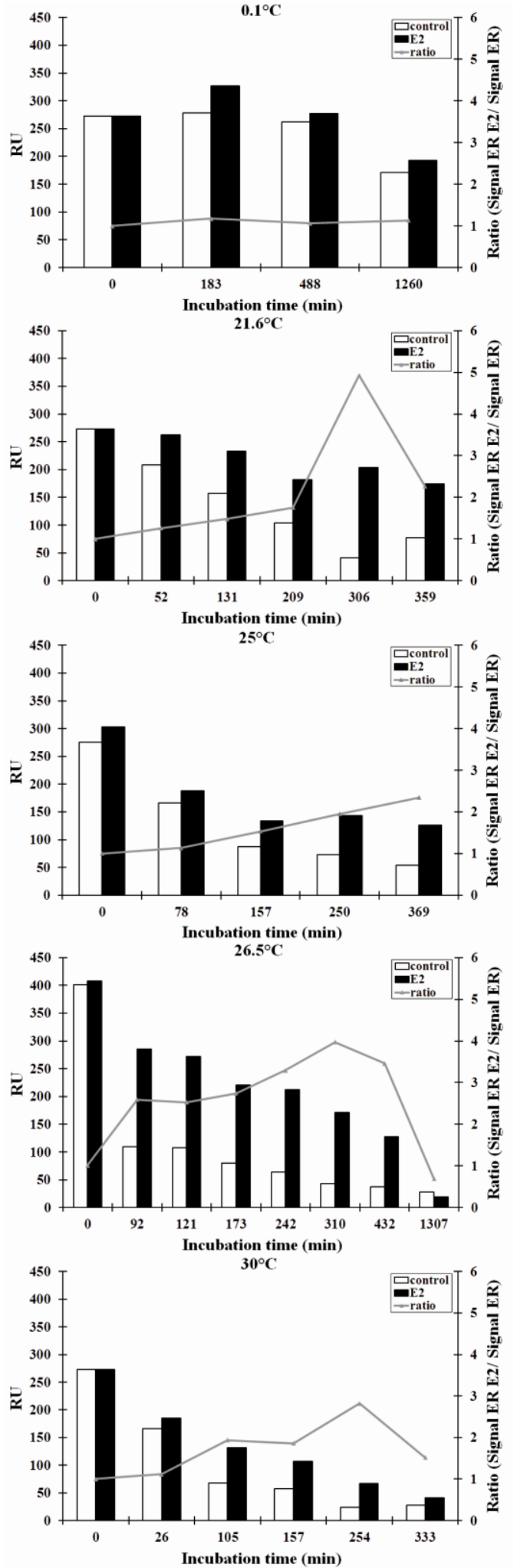
Fig. 6

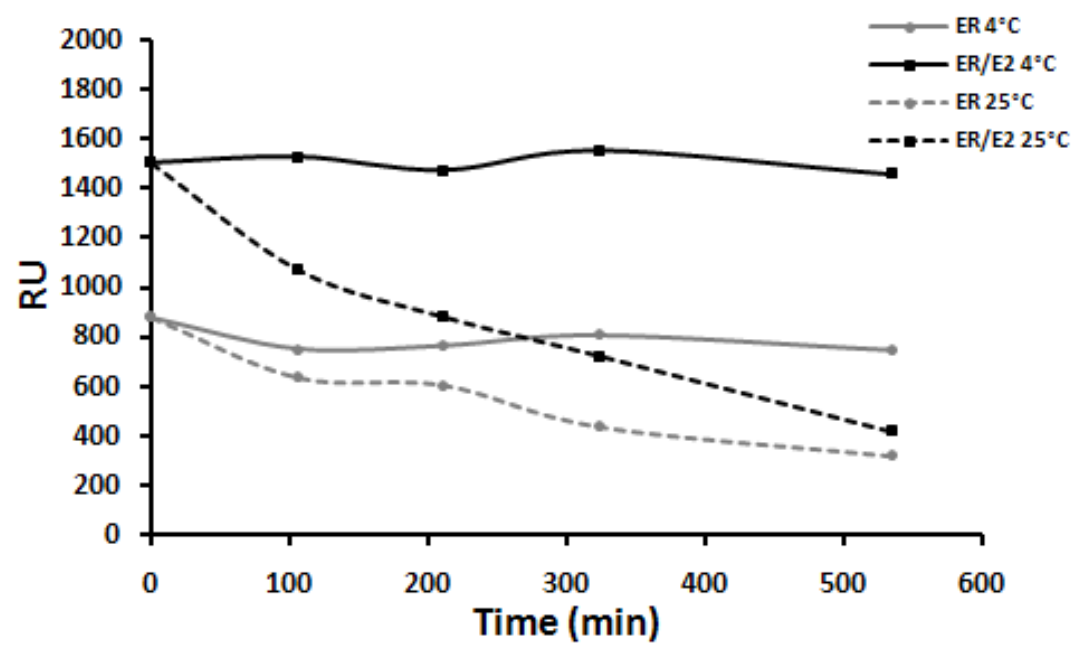

